\title{
Expression of 92-kD Type IV Collagenase/Gelatinase (Gelatinase B) in Osteoarthritic Cartilage and Its Induction in Normal Human Articular Cartilage by Interleukin 1
}

\author{
Masaaki Mohtai, * R. Lane Smith, " David J. Schurman, “ Yoshiaki Tsuji, ${ }^{\ddagger}$ Frank M. Torti, ${ }^{*}$ Nancy I. Hutchinson, \\ William G. Stetler-Stevenson," and Gregory I. Goldberg" \\ *Orthopaedic Research Laboratory, Division of Orthopaedic Surgery, Department of Functional Restoration, and ${ }^{\ddagger}$ Department of \\ Medicine, Stanford University School of Medicine, Stanford, California 94305; ${ }^{\ddagger}$ Veterans Affairs Medical Center, Palo Alto, California \\ 94304; \$ Department of Molecular Immunology, Merck Sharp \& Dohme Research Laboratories, Rahway, New Jersey 07065; "Tumor \\ Invasion and Metastasis Section, Laboratory of Pathology, National Cancer Institute, National Institutes of Health, Bethesda, \\ Maryland 20892; and 'Division of Dermatology, Washington University School of Medicine, St. Louis, Missouri 63110
}

\begin{abstract}
We report here that a 92-kD gelatinolytic metalloproteinase is expressed as protein and mRNA in human osteoarthritic cartilage, but not in normal adult articular cartilage. Western immunoblotting demonstrated that the $92-\mathrm{kD}$ gelatinolytic activity corresponded to 92-kD type IV collagenase/gelatinase (gelatinase B); mRNA for gelatinase B was identified by Northern blotting. Chondrocytes from normal cartilage also exhibited mRNA for 72-kD type IV collagenase/gelatinase (gelatinase A), tissue collagenase, and stromelysin-1, and these mRNAs were increased in osteoarthritic cartilage. Regional analysis of osteoarthritic cartilage samples from four individuals revealed that gelatinase B mRNA was expressed in grossly fibrillated areas; two of four nonfibrillated cartilage samples failed to exhibit the mRNA, but did have increased levels of mRNA for other neutral metalloproteinases. IL-1 $\alpha$ treatment of normal human cartilage explants or isolated chondrocytes induced increased levels of gelatinase $B$ and increased mRNA for tissue collagenase and stromelysin-1. Under identical conditions, mRNA levels for gelatinase $A$ were not increased indicating that regulation of this enzyme in human articular chondrocytes is distinct from that of other metalloproteinases. Our data showing expression of gelatinase $B$ in fibrillated cartilage suggest that it is a marker of progressive articular cartilage degradation in osteoarthritis. ( $J$. Clin. Invest. 1993. 92:179-185.) Key words: gelatinase $\bullet$ human articular cartilage $\bullet$ interleukin 1 - metalloproteinase $\bullet$ osteoarthritis
\end{abstract}

\section{Introduction}

Osteoarthritis (OA) ${ }^{1}$ is a disease of complex etiology that results in articular cartilage breakdown. Current experimental evidence suggests that, in addition to mechanical factors, pro-

Address reprint requests to Dr. R. Lane Smith, Orthopaedic Research Laboratory, Division of Orthopaedic Surgery, 300 Pasteur Drive, Room R-177, Stanford University Medical Center, Stanford, CA 94305-5326.

Received for publication 28 October 1992 and in revised form 1 February 1993.

1. Abbreviations used in this paper: APMA, 4-aminophenylmercuric acetate; OA, osteoarthritis; TPA, 12-O-tetradecanoylphorbol acetate.

J. Clin. Invest.

(C) The American Society for Clinical Investigation, Inc.

0021-9738/93/07/179/07 \$2.00

Volume 92, July 1993, 179-185 teolytic pathways contribute to loss of cartilage matrix in OA $(1,2)$. Many classes of proteases are capable of degrading components of cartilage, but the matrix metalloproteinases, active at neutral $\mathrm{pH}$ in the extracellular matrix, are considered to play a particularly important role (3).

The neutral metalloproteinase family contains at least two distinct interstitial collagenases ( tissue collagenase and neutrophil collagenase $)(4,5)$, two types of stromelysin (stromelysin 1 and 2) (6-10), a small proteinase PUMP-1 (10), and the 72-kD (11-13) and 92-kD (12, 14-20) type IV collagenases/ gelatinases. Structural analysis of the genes for these metalloproteinases demonstrates an evolutionary relationship between these enzymes (3). The neutral metalloproteinases degrade various components of the extracellular matrix, but vary with respect to substrate specificity. The metalloproteinases share a zinc-binding site, are secreted as proenzymes, and require activation in vitro by the action of proteinases (plasmin, kallikrein, mast cell tryptase, and trypsin) or nonproteolytic agents, such as organomercurial compounds, $N$-ethylmaleimide, oxidized glutathione, and hypochlorous acid. The activating agents perturb the interaction of a critical cysteine residue in a highly conserved propeptide domain of the metalloproteinases with the catalytic zinc atom (3). However, it remains unclear whether a unique agent is responsible for metalloproteinase activation in vivo.

With respect to neutral metalloproteinase activity in cartilage, chondrocyte-derived collagenase (21-23) and stromely$\sin (24,25)$ levels in OA are well characterized; secretion of these enzymes confers upon the chondrocytes the capability of degrading many components of the extracellular matrix, including type II collagen, fibronectin, laminin, and proteoglycans. Other enzymes, such as type IV collagenases/gelatinases, may influence the breakdown of cartilage in OA by accelerating degradation of matrix components or by digesting collagenase- or stromelysin-resistant matrix molecules, such as collagen type XI $(26,27)$. Although type IV collagenase/gelatinase activities are reported in rabbit cartilage $(28,29)$, little information exists on expression of the type IV collagenase/gelatinases in human articular cartilage in normal or pathological conditions.

In the present study, we demonstrate for the first time that nonfibrillated and fibrillated osteoarthritic cartilage produces a 92-kD type IV collagenase/gelatinase (gelatinase B; EC 3.4.24.35) that is not secreted by normal articular cartilage. A 72-kD type IV collagenase/gelatinase (gelatinase A; EC 3.4.24.24) is produced by both normal and osteoarthritic cartilage. Expression of gelatinase B is inducible in normal human articular cartilage and in isolated chondrocytes by addition of 
the cytokine, IL-1 $\alpha$, which also stimulates synthesis of tissue collagenase and stromelysin-1 $(30,31)$. Our data suggest that gelatinase $\mathrm{B}$ may be a marker of progressive articular cartilage degradation in OA.

\section{Methods}

Osteoarthritic cartilage organ culture. Osteoarthritic cartilage samples were obtained from arthritic patients undergoing total joint arthroplasty. In each case, full-thickness cartilage slices (40-50 mg wet weight) were made, and cultured in serum-free medium which consisted of DME/F12(1:1) medium, $50 \mu \mathrm{g} / \mathrm{ml}$ of gentamicin, $2 \times 10^{-8}$ $M$ selenium, and a lipid supplement (32) in 24-cluster microwell culture plates (Costar, Cambridge, MA) for $3 \mathrm{~d}$. The medium was renewed on the second day of culture; the renewed culture medium was harvested on the fourth day of culture, and kept frozen at $-20^{\circ} \mathrm{C}$ until use.

Normal human articular cartilage organ culture. Normal human articular cartilage was obtained at autopsy within $24 \mathrm{~h}$ of death and processed immediately. Knee cartilage from four adults (ages 35-65 yr) were studied. All normal cartilage used had a normal macroscopic appearance. None of these knees showed any overt signs of cartilage degeneration. None of the patients surveyed had any clinical history of chemotherapy or radiotherapy. Full-thickness cartilage slices (40-50 $\mathrm{mg}$ wet weight), similar in size to the OA cartilage slices, were distributed in 24-cluster microwell culture plates and cultured in the serumfree medium for $3 \mathrm{~d}$. The medium was renewed on the second day of culture, and normal cartilage $(n=4)$ slices from four individuals were challenged with IL- $\alpha(100 \mathrm{U} / \mathrm{ml}$, Genzyme Corp., Boston MA) for $2 \mathrm{~d}$.

Cell culture. Normal human articular chondrocytes were isolated from the samples described above by sequential digestion at $37^{\circ} \mathrm{C}$, with $1 \mathrm{mg} / \mathrm{ml}$ of trypsin (1:250, Gibco, Grand Island, NY) for $1 \mathrm{~h}$ and 2 $\mathrm{mg} / \mathrm{ml}$ of each collagenase (CLS-II and CLS-IV; Worthington Biochemical Corp., Freehold, NJ) for 12-16 h. Cells were plated at 1.5 $\times 10^{5}$ cells $/ \mathrm{cm}^{2}$ on poly-L-lysine-coated dishes and cultivated in the serum-free medium. After $3 \mathrm{~d}$, the medium was replaced, followed by culture in the presence or absence of IL- $1 \alpha(100 \mathrm{U} / \mathrm{ml})$ in the serumfree medium for $48 \mathrm{~h}$. Human keratinocytes of neonatal foreskins were a generous gift of Dr. T. Iwasaki (Department of Dermatology, Stanford University). The cells were cultured in serum-free MCDB 153 medium with $0.1 \mathrm{mM}$ calcium, $30 \mu \mathrm{g} / \mathrm{ml}$ of bovine pituitary extract and supplements (Clonetics Corp., San Diego, CA). The cells were treated with $50 \mathrm{ng} / \mathrm{ml}$ of 12-O-tetradecanoylphorbol acetate (TPA) for $24 \mathrm{~h}$.

Zymographic analysis of metalloproteinases. Zymography of secreted proteins by electrophoresis in $10 \%$ SDS-polyacrylamide gels impregnated with $1 \mathrm{mg} / \mathrm{ml}$ type I gelatin from porcine skin (Sigma Chemical Co., St. Louis, MO) was used to demonstrate the presence of gelatinolytic metalloproteinases in medium from cartilage organ culture (33). Aliquots of medium were mixed with Laemmeli sample buffer containing $2.5 \%$ SDS without $\beta$-mercaptoethanol and electrophoresed without boiling under nonreducing conditions at $4^{\circ} \mathrm{C}$, constant current $20 \mathrm{~mA}$. After electrophoresis, gels were washed in $2.5 \%$ Triton X-100 for $30 \mathrm{~min}$ to allow proteins to renature. Gels were then incubated overnight in substrate buffer ( $50 \mathrm{mM}$ Tris, $\mathrm{pH} 8.0,10 \mathrm{mM} \mathrm{CaCl}_{2}$ ) at $37^{\circ} \mathrm{C}$. After incubation, gels were stained with Coomassie Blue R250 to reveal zones of lysis within the gelatin matrix. 1,10 phenanthroline ( 2 $\mathrm{mM})$, PMSF ( $1 \mathrm{mM})$, or pepstatin ( $1 \mathrm{mM}$ ) was added to the substrate buffer to identify which classes of proteinases were responsible for lysis of the substrate in the gels (34). Some of the conditioned medium samples were incubated with $0.5 \mathrm{mM}$ 4-aminophenylmercuric acetate (APMA) for $3 \mathrm{~h}$ at $37^{\circ} \mathrm{C}$ to activate latent protease before loading to the substrate gels $(35)$.

Immunoblotting. Supernatants from organ cultures were concentrated using a microconcentrator (Centricon-30; Amicon, Beverly, MA). Protein concentration was measured using a protein assay kit (Bio-Rad Laboratories, Richmond, CA ). $20 \mu \mathrm{g}$ of protein was resus- pended in loading dye ( $125 \mathrm{mM}$ Tris- $\mathrm{HCl}$ [ $\mathrm{pH} 6.8$ ], 4\% [wt/vol] SDS, $0.01 \%$ bromphenol blue, $20 \%$ glycerol ), reduced ( $10 \% \beta$-mercaptoethanol), heated for $2 \mathrm{~min}$ at $95^{\circ} \mathrm{C}$, loaded, and electrophoresed on a $10 \%$ polyacrylamide gel. After electrophoresis, the proteins were transferred to nitrocellulose membrane (Schleicher \& Schuell, Inc., Keene, NH) in electroblotting buffer ( $20 \mathrm{mM}$ Tris ( $\mathrm{pH} 8.0$ ), $150 \mathrm{mM}$ glycine, $20 \%$ $\mathrm{MeOH}$ ) overnight at $250 \mathrm{~mA}$. Western blots were blocked in a milk solution ( $5 \%$ nonfat dry milk, $150 \mathrm{mM} \mathrm{NaCl}, 50 \mathrm{mM}$ Tris, $0.05 \%$ Tween) at room temperature until solidified. The blots were exposed to a primary antibody against gelatinase B (36) and subsequently developed by using goat anti-rabbit IgG horseradish peroxidase in conjunction with an enhanced chemiluminescence Western blotting detection system (Amersham International, Amersham, UK).

Northern blot analysis. Total RNA was obtained from chondrocytes isolated from normal cartilage or from osteoarthritic cartilage samples, as described above. To evaluate mRNA levels within focal areas of $\mathrm{OA}$, cartilage samples from four individuals were separated and analyzed independently based on the presence or absence of gross fibrillation. The level of fibrillation was determined visually by surface inspection. RNA was extracted from cells using a solution containing 4 $\mathrm{M}$ guanidine isothiocyanate, $25 \mathrm{mM}$ sodium citrate, $0.2 \%$ (wt/ vol) $n$-lauroylsarcosine, and $0.7 \%(\mathrm{vol} / \mathrm{vol}) \beta$-mercaptoethanol, followed by centrifugation at $35,000 \mathrm{rpm}$ for $20 \mathrm{~h}$ through a $5.6 \mathrm{M}$ cesium chloride cushion. The RNA pellet was solubilized in water, sequentially extracted with $4: 1$ ( $\mathrm{vol} / \mathrm{vol}$ ) chloroform/n-butanol, $1: 1$ (vol/ vol) phenol/chloroform, and chloroform. The aqueous phase containing RNA was adjusted to $0.3 \mathrm{M}$ sodium acetate. RNA was precipitated overnight with $2.5 \times$ vols of absolute ethanol. The concentration of RNA was determined by spectrophotometric absorption at $260 \mathrm{~nm} .10$ $\mu \mathrm{g}$ of total RNA from each sample was separated on a formamide/formaldehyde agarose gel and transferred to a nitrocellulose membrane by capillary blotting overnight. The membranes were air-dried, then baked at $80^{\circ} \mathrm{C}$ for $2 \mathrm{~h}$. A cDNA for gelatinase $A$ was isolated from the cDNA library of primary human synovial fibroblasts as described before (37). A 900-bp Pst I fragment of gelatinase A, a 2.3-kb Xba I fragment of gelatinase B (17), a 1.5-kb Xba I fragment of tissue collagenase (37), and a 1.8-kb Pst I fragment of stromelysin-1 (37) were ${ }^{32}$ P-labeled by random priming (Amersham International). Each probe had a specific activity between 4 and $6 \times 10^{8} \mathrm{cpm} / \mu \mathrm{g}$. Blots were hybridized at $42^{\circ} \mathrm{C}$ overnight and washed at $55^{\circ} \mathrm{C}$ in $0.5 \times \mathrm{SSC}+0.1 \%$ SDS for $1 \mathrm{~h}$. The membranes were exposed to Kodak X-Omat films with a Du Pont light intensifying screen at $-80^{\circ} \mathrm{C}$. To strip blots, nitrocellulose membranes were put into boiled $0.1 \times$ SSC $+0.1 \%$ SDS until the solution cooled.

Densitometric analysis. Autoradiographic results generated from Northern blots were quantified using a densitometer (LKB Instruments, Inc., Gaithersburg, MD) to determine relative levels of mRNA expression. The densitometric values obtained for each osteoarthritic cartilage sample, fibrillated and nonfibrillated, were divided by the average value obtained for four normal cartilage samples corresponding to the cDNA being tested. The normal values were normalized to 1.0 for comparison.

\section{Results}

Arthritic articular cartilage produces $a 92-k D$ gelatinase and a $72-k D$ gelatinase. Gelatin zymograms of conditioned culture medium from four arthritic cartilage samples demonstrated 92-kD gelatinase activity in all samples; culture medium from four normal cartilage samples did not exhibit this activity (Fig. 1 , large arrow). These observations have now been extended to six other patients (data not shown). Some OA samples showed an 82-kD gelatinolytic band, indicative of the active form of the 92-kD enzyme (Fig. 1, lane 8, small arrow). The 92-kD gelatinase was shown to be a metalloprotease by the complete loss of enzyme activity when the zymogram was incubated in 


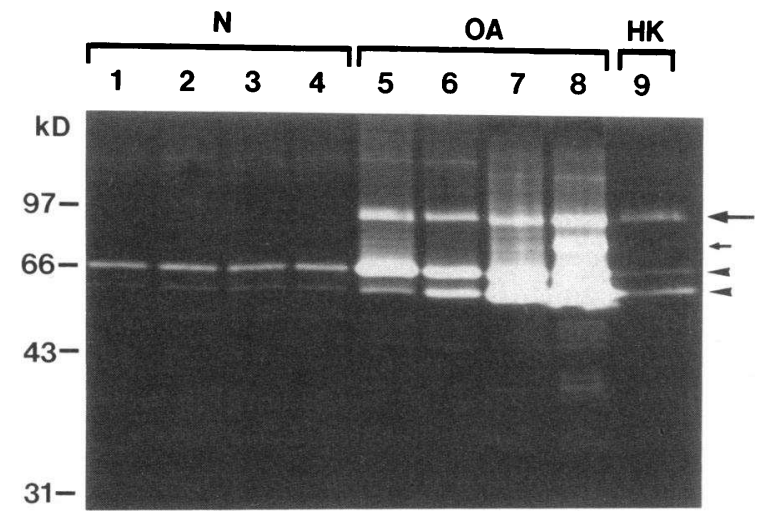

Figure 1. Expression of a $92-\mathrm{kD}$ gelatinase by osteoarthritic cartilage. Cartilage slices were cultured in the serum-free medium for $3 \mathrm{~d}$, as described in Methods, and conditioned medium samples were electrophoresed on a gelatin-substrate gel. Zones of clearing represent gelatinolytic activity. Four normal cartilage cultures $(N$, lanes $1-4)$ did not show the $92-\mathrm{kD}$ gelatinase (large arrow), whereas four osteoarthritic cartilage cultures did ( $O A$, lanes 5-8). TPA-stimulated human keratinocyte-conditioned medium was run as a positive control for the 92-kD gelatinase (lane 9). 72-kD gelatinase appeared as a doublet of gelatinolytic activity at 66 and $62 \mathrm{kD}$ (arrowheads). The $72-\mathrm{kD}$ gelatinase was expressed by all cartilage samples and was increased in osteoarthritic cartilage. One OA sample showed an additional 82-kDa gelatinolytic band, representative of the active form of the $92-\mathrm{kD}$ gelatinase (lane 8 , small arrow). Molecular mass markers are in the far left lane.

the presence 1.10 phenanthroline (Fig. 2). PMSF, a serine protease inhibitor, and pepstatin $\mathrm{A}$, an acid proteinase inhibitor, had no effect on the $92-\mathrm{kD}$ gelatinase activity under similar conditions.

In contrast to the $92-\mathrm{kD}$ enzyme, $72-\mathrm{kD}$ gelatinase was expressed by all cartilage samples and was increased in osteoarthritic cartilage (Fig. 1, arrowheads). The 72-kD gelatinase appeared frequently as a doublet of gelatinolytic activity at 66 and $62 \mathrm{kD}$ on SDS-PAGE under nonreduced conditions (12). The 72-kD enzyme was also inhibited by 1,10 phenanthroline (Fig. 2).

Treatment of the medium aliquots with the mercurial, APMA, was carried out to activate the zymogens of matrix metalloproteinases. APMA transformed the $92-\mathrm{kD}$ gelatinase into a $82-\mathrm{kD}$ species (Fig. 3). In contrast, the $72-\mathrm{kD}$ gelatinase became a triplet of gelatinolytic activity at 66,64 , and $62 \mathrm{kD}$ after APMA treatment (Fig. 3).

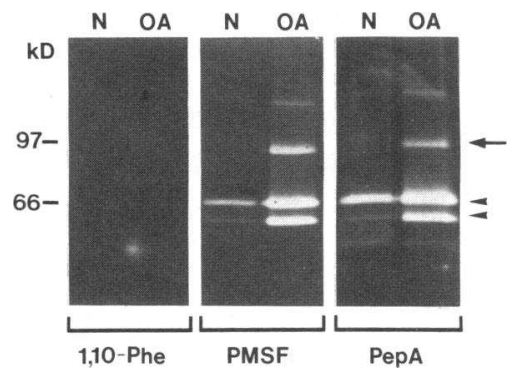

Figure 2. Identification of the gelatinolytic enzymes as metalloproteinases. After electrophoresis of conditioned medium samples from normal $(N)$ and osteoarthritic cartilage $(O A)$, gelatin substrate gels were incubated in the presence of $2 \mathrm{mM} 1,10$

phenanthroline (1,10-Phe), $1 \mathrm{mM}$ PMSF, $1 \mathrm{mM}$ pepstatin A (Pep $A$ ). All gelatinases, including the $92-\mathrm{kD}$ ( arrow) and $72-\mathrm{kD}$ gelatinase (arrowheads) were inhibited by 1,10 phenanthroline but resistant to inhibition by other proteinase inhibitors.

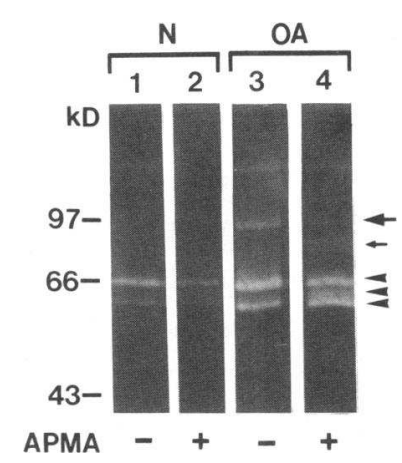

Figure 3. Effects of APMA on gelatinases. Before loading, conditioned medium samples were incubated without (lanes 1 and 3) or with $0.5 \mathrm{mM}$ APMA for $3 \mathrm{~h}$ at $37^{\circ} \mathrm{C}$ to activate latent proteases (lanes 2 and 4). APMA transformed the $92-\mathrm{kD}$ gelatinase (large arrow) into a 82-kD species ( small arrow). In contrast, the $72-\mathrm{kD}$ gelatinase became a triplet of gelatinolytic activity at 66,64 , and $62-\mathrm{kD}$ by APMA treatment (arrowheads).
The higher molecular weight gelatinase produced by osteoarthritic cartilage comigrated with the $92-\mathrm{kD}$ gelatinase secreted by human foreskin keratinocytes stimulated with TPA (17) (Fig. 1). Western blot analysis was carried out using a polyclonal antibody against gelatinase $B$ to determine the immunologic cross-reactivity between chondrocyte and keratinocyte gelatinases (Fig. 4). The 92-kD band in osteoarthritic cartilage culture medium was recognized by this antibody whereas no such band was present in normal cartilage culture medium (Fig. 4, arrow). In addition, in the OA cartilage, two less distinct bands and one prominent band were present at regions near $69 \mathrm{kD}$ (Fig. 4, arrowheads). Conditioned medium from TPA-stimulated keratinocyte cultures exhibited the $92-\mathrm{kD}$ gelatinase B and served as a positive control.

Northern blot analysis of neutral metalloproteinase $m R N A$. Northern blot analysis showed that mRNA for gelatinase B was not expressed in normal chondrocytes, a finding consistent with zymographic and immunoblot results (Fig. 5). Normal and osteoarthritic cartilage chondrocytes expressed mRNA for 72-kD gelatinase A, tissue collagenase, and stromelysin-1. In addition, osteoarthritic chondrocytes showed increased levels of mRNA for each of these enzymes when compared with levels present in normal chondrocytes.

Separation of four osteoarthritic cartilage samples into different morphologic regions showed that the mRNA for gelati-

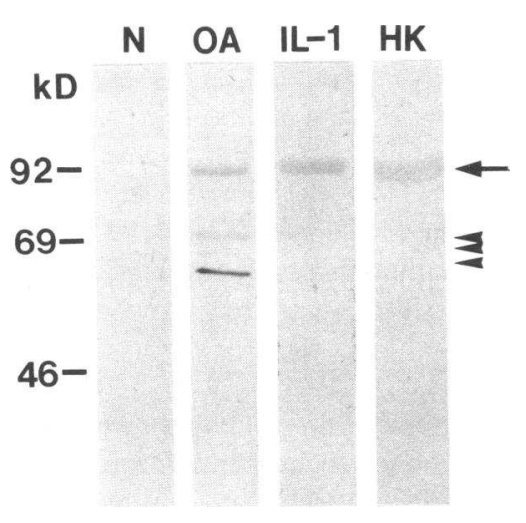

Figure 4. Cross-reactivity of the $92-\mathrm{kD}$ gelatinases from cartilage and TPA-stimulated keratinocytes. Conditioned medium samples from normal cartilage $(N)$, osteoarthritic cartilage $(O A)$, normal cartilage stimulated with IL- $1 \alpha$ $(I L-1)$, and human keratinocytes stimulated with TPA $(H K)$ were electrophoresed, transferred to nitrocellulose

membrane, and subjected to immunoblot analysis using a polyclonal anti-gelatinase B. The antibody identified a band at $92 \mathrm{kD}$ (arrow) in medium from osteoarthritic cartilage, normal cartilage stimulated with IL- $1 \alpha$, and keratinocyte cultures but showed no reactivity with medium from normal cartilage. In addition, in the osteoarthritic cartilage, two less distinct bands and one prominent band were present at regions near $69 \mathrm{kD}$ (arrowheads). 


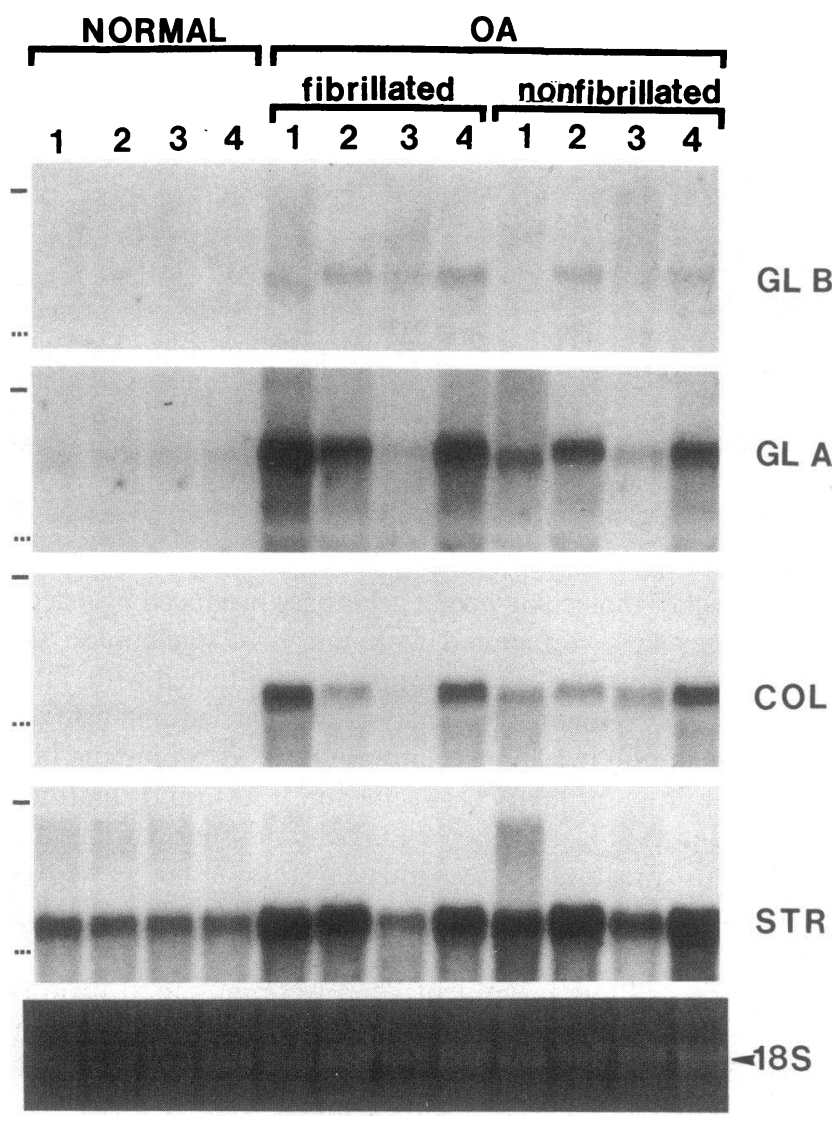

Figure 5. Northern blot analysis of neutral metalloproteinase expression in normal and osteoarthritic articular cartilage. Normal cartilage was from four individuals ( $N$, lanes $1-4)$. Osteoarthritic cartilage samples from four individuals were separated into fibrillated $(O A$, lanes 1-4) and nonfibrillated $(O A$, lanes $1-4)$ regions that were maintained as paired samples. RNA was extracted from each region separately. $10 \mu \mathrm{g}$ of total RNA from each sample was separated on formamide/formaldehyde agarose gel as described in Methods. Blots were probed sequentially with gelatinase B cDNA $(G L B)$, gelatinase A cDNA ( $G L A)$, tissue collagenase cDNA (COL), and stromelysin1 cDNA $(S T R)$. Intensity of the $18 \mathrm{~S}$ RNA staining by ethidium bromide is shown for comparison of total RNA loaded per lane. The location of $28 \mathrm{~S}$ and $18 \mathrm{~S}$ ribosomal RNA is shown by the small bars (solid, 28S; and dotted, 18S) to the left of the figure.

nase B was present in chondrocytes from all fibrillated osteoarthritic cartilage samples and in only two of four nonfibrillated osteoarthritic cartilage samples (Fig. 5). Chondrocytes from two nonfibrillated osteoarthritic cartilage samples failed to express mRNA for gelatinase $B$, although mRNA levels for gelatinase $A$, tissue collagenase, and stromelysin- 1 were elevated relative to the normal cartilage chondrocytes (Fig. 5: OA cases 1 and 3 ).

Densitometric analysis of the Northern blots showed that the relative levels of expression of metalloproteinases associated with osteoarthritic cartilage were elevated in both fibrillated and nonfibrillated cartilage. The levels of $\mathrm{mRNA}$ for gelatinase $A$ and tissue collagenase were increased in a range from 2to 25-fold in fibrillated osteoarthritic cartilage (Fig. 6); the corresponding samples of nonfibrillated OA cartilage typically matched the levels in the fibrillated cartilage (Fig. 6, connecting lines), although not in every case. Stromelysin-1 mRNA levels were also elevated in three of four samples, but the increases were only two- to threefold greater than levels in normal cartilage.

Regulation of gelatinase $B$ expression in normal cartilage and chondrocytes by $I L-1 \alpha$. Effects of IL- $1 \alpha$ on production of the gelatinases by normal cartilage explants and normal chondrocytes in high density culture were determined by comparative zymography of culture medium samples (Fig. 7). IL-1 $\alpha$ induced the production of gelatinase B by both normal cartilage and chondrocytes within $48 \mathrm{~h}$ (Fig. 7, large arrow). In addition to the induction of the $92-\mathrm{kD}$ gelatinase $\mathrm{B}, \mathrm{IL}-1 \alpha$ also increased levels of other gelatinases (bands at 50-55 kD, Fig. 7, triangles), possibly tissue collagenase and stromelysin-1. A band of gelatinolytic activity migrating at $120 \mathrm{kD}$ (Fig. 7, small arrow) was also increased by exposure to IL-1 $\alpha$. The bands located at 66 and $62 \mathrm{kD}$ were relatively unchanged by IL- $1 \alpha$ and likely represent migration of $72-\mathrm{kD}$ gelatinase $\mathrm{A}$ species under reduced conditions (12) (Fig. 7, arrowheads). Western blot analysis of the culture medium from IL- $1 \alpha$ stimulated normal cartilage showed that the newly produced $92-\mathrm{kD}$ enzyme was recognized by a polyclonal antibody against gelatinase $B$ (see Fig. 4). However, only the proenzyme was visible after IL-1 stimulation by Western blot.

mRNA expression patterns of the gelatinases in response to IL- $1 \alpha$ were also examined by Northern blot analysis (Fig. 8). mRNA for gelatinase B was inducible by IL- $1 \alpha$, consistent with zymographic and Western blot results. IL- $1 \alpha$ did not increase the expression of gelatinase $\mathrm{A}$, as previously reported for human tumor cells (38). Treatment with IL- $1 \alpha$ increased both tissue collagenase and stromelysin- 1 mRNA levels, as reported previously $(30,31)$.

\section{Discussion}

Our data demonstrated that osteoarthritic cartilage secreted 92-kD gelatinase $\mathrm{B}$, an enzyme not produced by normal adult human articular cartilage. However, IL- $1 \alpha$ induces expression of gelatinase B in normal cartilage. The properties of this enzyme are consistent with its being a neutral metalloproteinase. The $92-\mathrm{kD}$ enzyme was converted to a $82-\mathrm{kD}$ form by APMA treatment and its gelatinolytic activity was completely inhibited by 1,10 phenanthroline, but not by serine- or acid proteinase inhibitors. The enzyme was identified by Western blot as gelatinase B found in other cell lines (12, 14-20). We also showed the presence of $\mathrm{mRNA}$ for gelatinase $\mathrm{B}$ in osteoarthritic cartilage using Northern blot analysis. The fact that osteoarthritic cartilage produces gelatinase B is, to our knowledge, previously unreported. In addition, the Western blot of osteoarthritic cartilage showed the presence of three identifiable bands in the region of $69 \mathrm{kD}$. Recent studies of the $92-\mathrm{kD}$ gelatinase $B$ in a human fibrosarcoma cell line show that activation of the proenzyme results in an intermediate form of 83 $\mathrm{kD}$ and two active forms of 67 and $64 \mathrm{kD}$ (39). The latter fully activated species results from stromelysin activity and lacks both amino- and carboxy-terminal peptides; this form would be recognized in the Western blotting and may be represented as the prominent staining band in the osteoarthritic cartilage lane. The affinity-purified polyclonal antibody used in this study was generated from a synthetic peptide representing amino acids $397-414$ of gelatinase B (36), a region which would be preserved in the $64-\mathrm{kD}$ active form of the enzyme.

The presence of the $92-\mathrm{kD}$ proenzyme and species of active enzyme in OA cartilage are consistent with the hypothesis that 

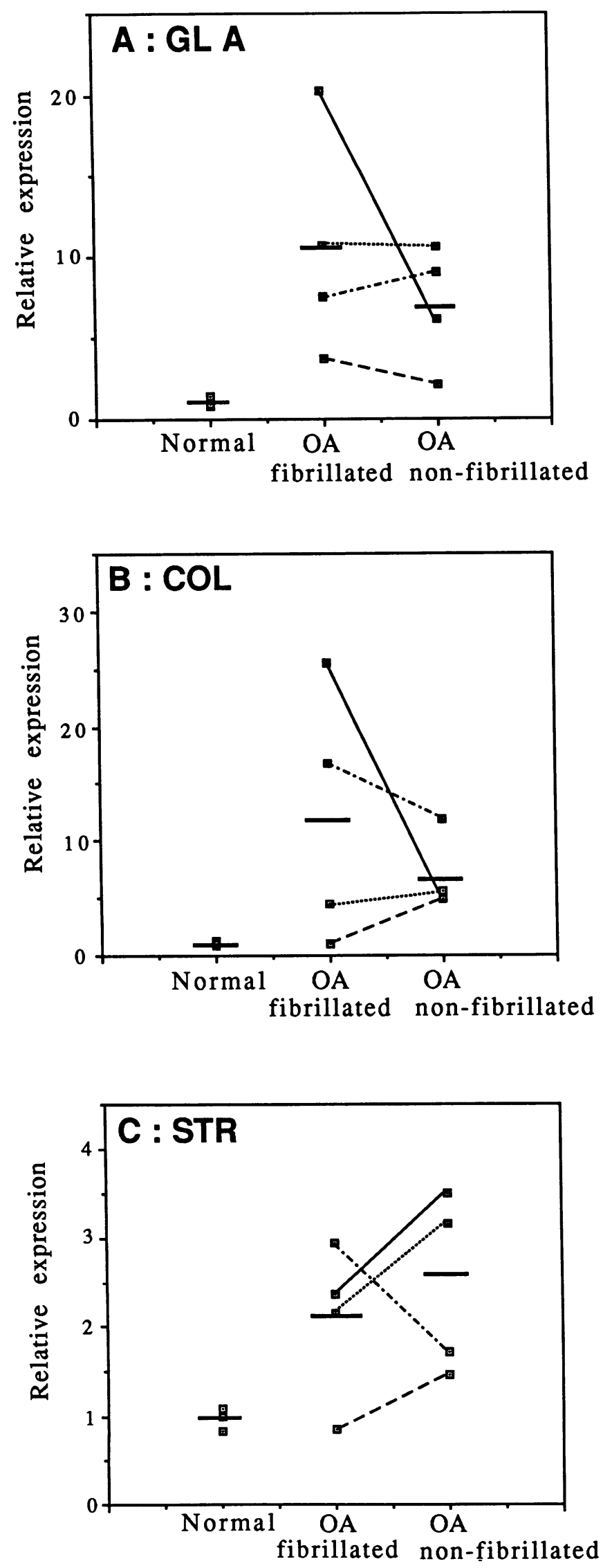

Figure 6. Densitometric analysis of the northern blots. The densitometric values obtained for each pair of osteoarthritic cartilage samples, fibrillated and nonfibrillated (see connecting lines), were divided by the average value obtained for four normal cartilage samples

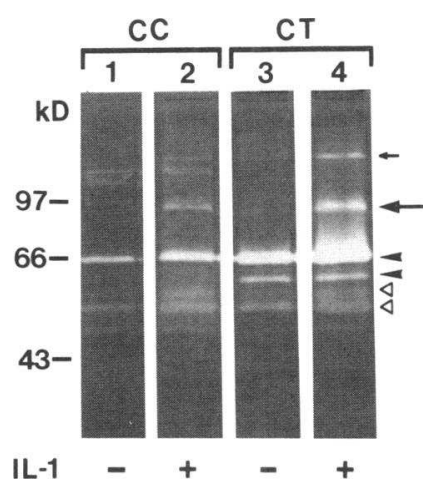

Figure 7. IL-1 $\alpha$ induction of the $92-\mathrm{kD}$ gelatinase. Normal human chondrocytes $(C C)$ and normal human cartilage $(C T)$ samples were cultured in serum-free medium without IL- $1 \alpha$ (lanes 1 and 3 ) or with IL- $\alpha(100 \mathrm{U} / \mathrm{ml}$, lanes 2 and 4 ) for $48 \mathrm{~h}$. IL- $1 \alpha$ induced expression of the $92-\mathrm{kD}$ gelatinase (large arrow). IL-1 $\alpha$ also increased levels of other gelatinases (bands at $50-55 \mathrm{kD}$, triangles), possibly tissue collagenase and stromelysin-1. A band of gelatinolytic activity migrating at $120 \mathrm{kD}$ was also increased by exposure to IL- $1 \alpha$ (small arrow). $72-\mathrm{kD}$ gelatinase was relatively unchanged by IL-1 $\alpha$ (arrowheads).

the metalloproteinases contribute importantly to the extracellular matrix degradation. Total endogenous proteoglycan and collagen-degrading activities are elevated in osteoarthritic cartilage relative to normal tissue and are locally increased at the erosion centers $(21,22,25)$. In OA, interstitial collagenase may initiate degradation of type II collagen ( 40 ) by cleaving at a site within the triple helix resulting in three-quarter and onequarter fragments (41) that denature spontaneously at body temperature. The resultant gelatin would then be susceptible to other metalloproteinases, such as gelatinase B, that have a high specific activity for denatured collagens $(14,16,17)$.

Our data support such a role for the gelatinase B since the mRNA levels for gelatinase B were elevated in chondrocytes from fibrillated cartilage but not in all samples of nonfibrillated cartilage. Chondrocytes from the nonfibrillated cartilage samples did, however, show elevated levels of mRNA for tissue collagenase and stromelysin-1, enzymes proposed to initiate cartilage degradation and activate other proenzymes (21-25, 39,42 ).

In addition to gelatinolytic activity, gelatinase B degrades various components of extracellular matrix, including collagen types IV, V, and XI $(14,16,17,43,44)$ and elastin $(45,46)$ that are resistant to collagenase and stromelysin. Therefore, expression of gelatinase B in OA cartilage may contribute importantly to the progressive breakdown of cartilage by degrading minor constituents of the extracellular matrix. Okada et al. (47) demonstrated that MMP-3 (stromelysin-1) is present in osteoarthritic cartilage and synovium and suggested that this enzyme is responsible for proteoglycan degradation. Our data demonstrating the presence of gelatinase $B$ in nonfibrillated and in fibrillated osteoarthritic cartilage may represent a condition in which stromelysin- 1 and other enzymes act in concert to degrade the structural backbone of the cartilage matrix.

We also demonstrated that osteoarthritic cartilage exhibits elevated levels of gelatinase A, an enzyme present in normal cartilage. However, the expression patterns of the gelatinase A appear distinct from gelatinase B. Although these enzymes

corresponding to the cDNA being tested. The normal values were set to 1.0 for comparison with OA values; the mean level of mRNA for each of the cartilage samples (normal, fibrillated, and nonfibrillated) are shown by horizontal bars. The relative levels of expression of gelatinase A $(A: G L A)$, tissue collagenase ( $B: C O L)$, and stromelysin-1 ( $C$ : $S T R$ ) were elevated in both fibrillated and nonfibrillated OA cartilage. 


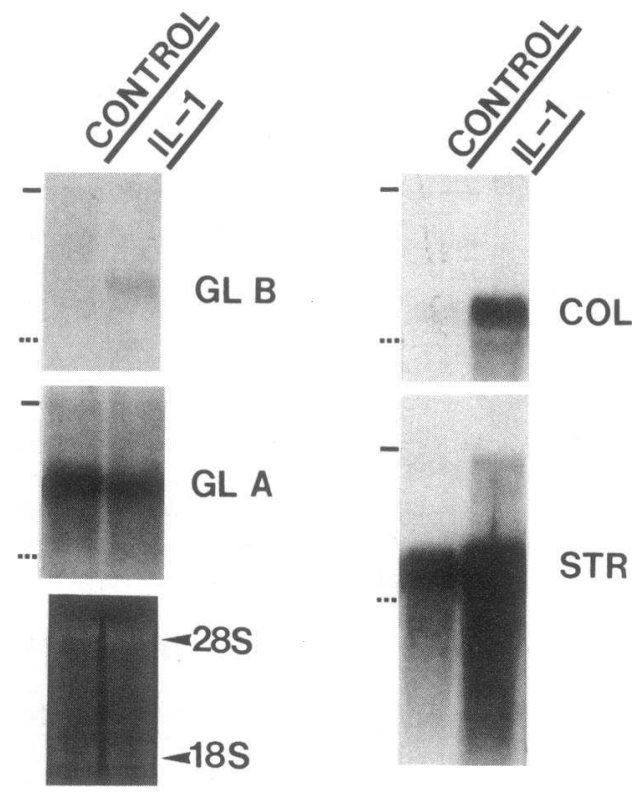

Figure 8. Northern blot analysis of neutral metalloproteinase expression in normal articular chondrocytes. Chondocytes were untreated (control) or treated with $100 \mathrm{U} / \mathrm{ml}$ of IL- $1 \alpha$ in serum-free medium for $48 \mathrm{~h}$ before RNA extraction. Blots were probed as described for Fig. 5. mRNA for gelatinase B $(G L B)$ was induced by IL-1 $\alpha$, although IL- $\alpha$ did not increase expression of gelatinase A (GL $A)$. Treatment with IL-1 $\alpha$ increased both tissue collagenase (COL) and stromelysin-1 (STR) mRNA levels. Intensity of the $28 \mathrm{~S}$ and $18 \mathrm{~S}$ RNA staining by ethidium bromide is shown for comparison of total RNA loaded per lane.

have similar substrate specificity profiles in vitro, the regulation of the two enzymes is distinct in other tissues. For example, alveolar macrophages and polymorphonuclear leukocytes have been found to secrete gelatinase B but not gelatinase A (17). Human skin fibroblasts secrete gelatinase A but not noticeable amounts of gelatinase B (17). Some transformed cells such as human fibrosarcoma cells HT-1080 secrete both enzymes (12), although secretion of the two enzymes by these cells is not coordinately regulated $(17,48)$.

Recent characterization of genes for the two enzymes demonstrates that they differ substantially from each other with respect to transcriptional control $(49,50)$. Our data suggest that gelatinase A may participate in the turnover of normal adult cartilage matrix, whereas gelatinase B may only play a role in the removal of denatured collagen fragments during degradation of cartilage matrix in OA.

Paracrine and/or autocrine mechanisms involving cytokines are proposed to be instrumental in degradation of human osteoarthritic cartilage. Among the cytokines, IL-1 appears to be an important mediator of inflammation and cartilage destruction. IL-1 stimulates the production of procollagenase and prostromelysin in chondrocytes $(30,31)$ and supresses the synthesis of aggregating proteoglycan and cartilage-specific collagen types II and IX $(51,52)$. In the present study IL- $1 \alpha$ added to the culture medium induced gelatinase $\mathrm{B}$ production by chondrocytes in normal human articular cartilage. Similar results were obtained from animal models $(15,29)$. IL- $1 \alpha$ did not increase the production of the 72-kD enzyme by normal human chondrocytes as previously reported for human tumor cells (38). Our data also support the idea that expression of gelatinase B, as in other tissues, is regulated independently of gelatinase $\mathrm{A}$.

The question remains as to the precise origin of the enzyme detected in the osteoarthritic cartilage. Evidence is available that other tissues such as the inflammatory cells, macrophages and polymorphonuclear leukocytes, secrete neutral metalloproteinases, including gelatinase B $(53,54)$. In an arthritic joint, the role of cartilage-derived enzymes versus enzymes originating from other tissues remains to be determined. The implication from our study is that chondrocytes retain full capacity for elaboration of gelatinase B and may contribute importantly to the disease process through its release.

In conclusion, chondrocytes in osteoarthritic cartilage secrete a $92-\mathrm{kD}$ gelatinase that is immunologically cross-reactive with gelatinase B secreted by activated keratinocytes. Normal chondrocytes can also produce the enzyme by the action of IL- $1 \alpha$. Our data showing expression of gelatinase B in all fibrillated cartilage, but not in some nonfibrillated cartilage that has elevated levels of gelatinase A, tissue collagenase, and stromelysin-1, suggests that gelatinase B may facilitate the progressive destruction of articular cartilage in OA.

\section{Acknowledgment}

We thank Dr. William J. Maloney for providing osteoarthritic cartilage samples.

This work was supported in part by grants AR-30796-06 and AR26833-10 from the National Institutes of Health. Dr. Torti is a recipient of a Clinical Investigator Award from the Department of Veterans Affairs.

\section{References}

1. Werb, Z. 1989. Proteinases and matrix degradation. In Textbook of Rheumatology. W. N. Kelly, E. D. Harris, Jr., S. Ruddy, and C. B. Sledge, editors. W. B. Saunders Co., Philadelphia. 300-321.

2. Dean, D. D. 1991. Proteinase-mediated cartilage degradation in osteoarthritis. Semin. Arthritis Rheum. 20:2-11.

3. Woessner, J. F., Jr. 1991. Matrix metalloproteinases and their inhibitors in connective tissue remodeling. FASEB J. 5:2145-2154.

4. Goldberg. G. I., S. M. Wilhelm, A. Kronberger, E. A. Bauer, G. A. Grant, and A. Z. Eisen. 1986. Human fibroblast collagenase: complete primary structure and homology to an oncogene transformation-induced rat protein. J. Biol. Chem. 261:6600-6605.

5. Hasty, K. A., T. F. Pourmotabbed, G. I. Goldberg, J. P. Thompson, D. G. Spinella, R. M. Stevens, and C. I. Mainardi. 1990. Human neutrophil collagenase: a distinct gene product with homology to other matrix metalloproteinases. J. Biol. Chem. 265:11421-11424.

6. Wilhelm, S. M., I. E. Collier, A. Kronberger, A. Z. Eisen, B. L. Marmer, G. A. Grant, E. A. Bauer, and G. I. Goldberg. 1987. Human skin fibroblast stromelysin: structure, glycosylation, substrate specificity, and differential expression in normal and tumorigenic cells. Proc. Natl. Acad. Sci. USA. 84:6725-6729.

7. Whitham, S. E., G. Murphy, P. Angel, H. J. Rahmsdorf, B. J. Smith, A. Lyons, T. Harris, Jr., J. J. Reynolds, P. Herrlich, and A. J. P. Docherty. 1987. Comparison of human stromelysin and collagenase by cloning and sequence analysis. Biochem. J. 240:913-916.

8. Matrisian, L. M. N. Glaichenhaus, M. C. Gesnel, and R. Breathnach. 1985. Epidermal growth factor and oncogenes induce transcription of the cellular mRNA in rat fibroblast. EMBO (Eur. Mol. Biol. Organ.) J. 4:1435-1440.

9. Matrisian, L. M., P. Leroy, C. Ruhlman, M. C. Gesnel, and R. Breathnach. 1986. Isolation of the oncogene and epidermal growth factor-induced transin gene: complex control in rat fibroblasts. Mol. Cell. Biol. 6:1679-1686.

10. Muller, D., B. Quantin, M. C. Gesnel, R. Milon-Collard, J. Abecassis, and R. Breathnach. 1988. The collagenase gene family in humans consists of at least four members. Biochem. J. 253:187-192.

11. Soto, T., L. A. Liotta, and K. Tryggvason. 1983. Purification and characterization of a murine basement membrane collagen-degrading enzyme secreted by metastatic tumor cells. J. Biol. Chem. 258:3058-3063.

12. Collier, I. E., S. M. Wilhelm, A. Z. Eizen, B. L. Marmer, G. A. Grant, J. L. Seltzer, A. Kronberger, C. He, E. A. Bauer, and G. I. Goldberg. 1988. H-ras oncogene-transformed human bronchial cells (TBE-1) secrete a single metallo- 
proteinase capable of degrading basement membrane collagen. J. Biol. Chem 263:6579-6587.

13. Huhtala, P., R. L. Eddy, Y. S. Fan, M. G. Byers, T. B. Shows, and K Tryggvason. 1990. Completion of the primary structure of the human type IV collagenese preproenzyme and assignment of the gene (CLG 4) to the q21 region of chromosome 16. Genomics. 6:554-559.

14. Hibbs, M. S., J. R. Hoidal, and A. H. Kang. 1987. Expression of a metalloproteinase that degrades native type $\mathrm{V}$ collagen and denatured collagens by cultured human alveolar macrophages. J. Clin. Invest. 80:1644-1650.

15. Murphy, G., R. M. Hembry, A. M. McGarrity, J. J. Reynolds, and B. Henderson. 1989. Gelatinase (type IV collagenase) immunolocalization in cells and tissue:use of an antiserum to rabbit bone gelatinase that identifies high and low $\mathrm{M}_{\mathrm{r}}$ forms. J. Cell Sci. 92:487-495.

16. Hibbs, M. S., K. A. Hasty, J. M. Seyer, A. H. Kang, and C. L. Mainardi 1985. Biochemical and immunological characterization of the secreted form of the human neutrophil gelatinase. J. Biol. Chem. 260:2493-2500.

17. Wilhelm, S. M. I. E. Collier, B. L. Marmer, A. Z. Eizen, G. A. Grant, and G. I. Goldberg. 1989. SV40-transformed human lung fibroblasts secrete a 92-kDa type IV collagenase which is identical to that secreted by normal human macrophages. J. Biol. Chem. 264:17213-17221.

18. Moll, U. M., G. L. Youngleib, K. B. Rosinsky, and J. P. Quifley. 1990 Tumor promoter-stimulated $M_{\mathrm{r}} 92,000$ gelatinase secreted by normal and malig nant human cells: isolation and characterization of the enzyme from HT1080 tumor cells. Cancer Res. 50:6162-6170.

19. Davis, G. E., and B. M. Martin. 1990. A latent Mr 94,000 gelatin-degrading metalloproteinase induced during differentiation of HL-60 promyelocytic leukemia cells: a member of the collagenase family of enzymes. Cancer Res. 50:1113-1120.

20. Lyons, I. G., B. Birkedal-Hansen, W. G. I. Moore, R. L. O'Grady, and H. Birkedal-Hansen. 1991. Characteristics of a 95-kDa matrix metalloproteinase produced by mammary cartinoma cells. Biochemistry. 30:1449-1456.

21. Ehrlich, M. G., H. J. Mankin, H. Jones, R. Wright, C. Crispen, and G Vigliani. 1977. Collagenase and collagenage inhibitors an osteoarthritic and normal human cartilage. J. Clin. Invest. 59:226-233.

22. Pelletier, J. P., J. Martel-Pelletier, and D. S. Howell, L. Ghandur-Mnaymnen, J. E. Enis, and J. F. Woessner. 1983. Collagenase and collagenolytic activity in human osteoarthritic cartilage. Arthritis Rheum. 26:63-68.

23. Dodge, G. R., and A. R. Pool. 1989. Immunohistochemical detection and immumochemical analysis of type II collagen degradation in human normal, rheumatoid and osteoarthritic cartilages and in explants of bovine articular cartilage cultured with interleukin-1. J. Clin. Invest. 83:647-661.

24. Sapolsky, A. I., H. Keiser, D. S. Howell, and J. F. Woessner Jr. 1976 Metalloproteinases of human articular cartilage that digest cartilage proteoglycan at neutral and acid pH. J. Clin. Invest. 58:1030-1041.

25. Martel-Pelletier, J., J. P. Pelletier, J. M. Cloutier, D. S. Howell, L. Ghandur-Mnaymneh, and J. F. Woessner, Jr. 1984. Neutral proteases capable of proteoglycan digesting activity in osteoarthritic and normal human articular cartilage. Arthritis Rheum. 27:305-312.

26. Burgeson, R. W., and D. W. Hollister. 1979. Collagen heterogeneity in human cartilage: Identification of several new collagen chains. Biochem. Biophys. Res. Commun. 87:1124-1131.

27. Mendler, M., S. G. Eich-Bender, L. Vaughan, K. H. Winterhalter, and P. Bruckner. 1989. Cartilage contains mixed fibrils of collagen types II, IX and XI. J. Cell Biol. 108:191-197.

28. Sapolsky, A. I., M. F. Sheff, K. Matsuda. D. S. Howell, R. W. Moskowitz, V. M. Goldberg, D. P. Norby, and C. J. Malemud. 1983. 'Gelatinase-like' activity from articular chondrocytes in monolayer culture. Biochim. Biophys. Acta $762: 227-231$

29. Lefebvre, V., C. Peeters-Joris, and G. Vaes. 1991. Production of gelatindegrading matrix metalloproteinases ('type IV collagenases') and inhibitors by articular chondrocytes during their dedifferentiation by serial subcultures and under stimulation by interleukin-1 and tumor necrosis factor a. Biochim. Biophys. Acta. 1094:8-18.

30. Murphy, G., R. M. Hembry, and J. J. Reinolds. 1986. Characterization of a specific antiserum to rabit stromelysin and demonstration of the synthesis of collagenase and stromelysin by stimulated rabit articular chopndrocytes. Coll. Relat. Res. 6:351-364.

31. Schnyder, J., T. Payne, and C. A. Dinarello. 1987. Human monocyte or recombinant interleukin I's are specific for the secretion of a metalloproteinase from chondrocytes. J. Immunol. 138:496-503.

32. Jones, D. G., and R. L. Smith. 1990. Stimulation of adult chondrocyte metabolism by a thyroid-derived factor. J. Orthop. Res. 8:227-233.

33. Chin, J. R., G. Murphy, and Z. Werb. 1985. Stromelysin, a connective tissue-degrading metalloendopeptidase secreted by stimulated rabbit synovial fibroblasts in parallel with collagenase. J. Biol. Chem. 260:12367-12376.
34. Barrett, A. J. 1977. Use of inhibitors in the classification of endopeptidases. In Proteinases in Mammalian Cells and Tissues. A. J. Barrett, editor. North-Holland Publishing Co., Amsterdam. 15-18.

35. Ishibashi, M., A. Ito, K. Sakyo, Y. Mori. 1987. Procollagenase activator produced by rabbit uterine cervical fibroblasts. Biochem. J. 241:527-534.

36. Corcoran, M. L., W. G. Stetler-Stevenson, P. D. Brown, and L. M. Wahl 1992. Interleukin 4 inhibition of prostaglandin $E_{2}$ synthesis blocks interstitial collagenase and $92-\mathrm{kDa}$ type IV collagenase/gelatinase production by human monocytes. J. Biol. Chem. 267:515-519.

37. MacNaul, K. L., N. Chartrain, M. Larks, M. J. Tocci, N. I. Hutchinson. 1990. Discoordinate expression of stromelysin, collagenase, and tissue inhibitor of metalloproteinases- 1 in rheumatoid human synovial fibroblasts: synergistic effects of interleukin- 1 and tumor necrosis factor- $\alpha$ on stromelysin expression. $J$. Biol. Chem. 265:17238-17245.

38. Brown, P. D., A. T. Levy, I. M. K. Margulies, L. A. Liotta, and W. G Stetler-Stevenson. 1990. Independent expression and cellular processing of $M$ 72,000 type IV collagenase and interstitial collagenase in human tumorigenic cell lines. Cancer Res. 50:6184-6191.

39. Okada, Y., Y. Gonoji, K. Naka, K. Tomita, I. Nakanishi, K. Iwata, K. Yamashita, and T. Hayakawa. 1992. Matrix metalloproteinase 9 (92-kDa gelatinase/type IV collagenase) from HT 1080 human fibrosarsoma cells. J. Biol. Chem. 267:21712-21719.

40. Okada, Y., H. Nagase, and E. D. Harris, Jr. 1983. A metalloproteinase from human rheumatoid synovial fibroblasts that digests connective tissue matrix components: purification and characterization. J. Biol. Chem. 261:1424514255

41. Gross, J., and Y. Nagai. 1965. Specific degradation of the collagen molecle by tadpole collagenolytic enzymes. Proc. Natl. Acad. Sci. USA. 54:1197-1204.

42. Ogata, Y., J. J. Enghild and H. Nagase. 1992. Matrix metalloproteinase 3 (stromelysin) activates the precursor for the human matrix metalloproteinase 9 . J. Biol. Chem. 267:3581-3584

43. Murphy, G., J. J. Reynolds, U. Bretz, and M. Baggiolini. 1982. Partial purification of collagenese and gelatinase from human polymorphonuclear leucocytes: analyses of their actions on soluble and insoluble collagens. Biochem. J. 203:209-221.

44. Murphy, G., R. Ward, R. M. Hembry, and J. J. Reynolds, K. Kuhn, and K. Tryggvason. 1989. Characterization of gelatinase from pig polymorphonuclear leucocytes. Biochem. J. 258:463-472.

45. Murphy, G., M. I. Cockett, R. V. Ward, and A. J. P. Docherty. 1991 Matrix metalloproteinase degradation of elastin, type IV collagen and proteoglycan: a quantitative comparison of the activities of $95 \mathrm{kDa}$ and $72 \mathrm{kDa}$ gelatinases. stromelysins- 1 and -2 and punctuated metalloproteinase (PUMP) Biochem. $J$. 277:277-279.

46. Senior, R. M., G. L. Griffin, C. J. Fliszer, S. D. Shapiro, G. I. Goldberg, and H. G. Welgus. 1991. Human 92- and 72-kilodalton type IV collagenases are elastases. J. Biol. Chem. 266:7870-7875.

47. Okada, Y., M. Shinmei, O. Tanaka, K. Naka, A. Kimura, I. Nakanishi, M. T. Bayliss, K. Iwata, and H. Nagase. 1992. Localization of matrix metalloproteinase 3 (stromelysin) in osteoarthritic cartilage and synovium. Lab. Invest. 66:680-690.

48. Yamagata, S., R. Tanaka, Y. Ito, and S. Shimizu. 1989. Gelatinases of murine metastatic tumor cells. Biochem. Biophys. Res. Commun. 158:228-234.

49. Huhtala, P., L. T. Chow, and K. Tryggvason. 1990. Structure of the human type IV collagenese gene. J. Biol. Chem. 265:11077-11082.

50. Huhtala, P., A. Tuuttila, L. T. Chow, J. Lohi, J. Keski-Oja, and K. Tryggvason. 1991. Complete structure of the human gene for 92-kDa Type IV collagenese: divergent regulation of expression for the 92- and 72-kilodalton enzyme genes in HT-1080 cells. J. Biol. Chem. 266:16485-16490.

51. Tyler, J. A. 1985. Articular cartilage cultured with catabolin (pig interleukin 1 ) synthesizes a decreased number of normal proteoglycan molecules. Biochem. J. 227:869-878.

52. Goldring. M. B., J. Birkhead, L. J. Sandel, T. Kimura, and S. M. Krane. 1988. Interleukin 1 supresses expression of cartilage-specific type II and IX collagens and increases type I and III collagens in human chondrocytes. J. Clin. Invest. 82:2026-2037.

53. Welgus, H. G., E. J. Campbell, J. D. Cury, A. Z. Eisen, R. M. Senior, S. M. Wilhelm, and G. I. Goldberg. 1990. Neutral metalloproteinases produced by human mononuclear phagocytes: enzyme profile, regulation, and expression during cellular development. J. Clin. Invest. 86:1496-1502.

54. Goldberg, G. I., A. Strongin, I. E. Collier, L. T. Genrich, and B. L. Marmer. 1992. Interaction of 92-kDa type IV collagenase with the tissue inhibitor of metalloproteinases prevents dimerization, complex formation with interstitial collagenase, and activation of the proenzyme with stromelysin. J. Biol. Chem 267:4583-4591. 